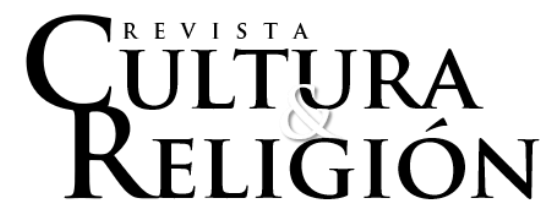

Vol. XV, No 1 (2021) pp. 1-43

Recibido: 20 de marzo, 2020

Aceptado: 5 de febrero, 2021

\title{
EVANGÉLICOS Y CRISIS DE LA DEMOCRACIA: DISCURSOS INSTITUCIONALES Y POSICIONAMIENTO POLÍTICO EN EL CONTEXTO DEL ESTALLIDO SOCIAL EN CHILE*
}

Evangelicals and the crisis of democracy: Institutional discourses and political positioning in the context of Chile's social upheaval

\author{
Luis Bahamondes González** \\ Centro de Estudios Judaicos, \\ U. de Chile \\ ORCID: 0000-0001-5599-9331
}

\author{
Luis Aránguiz Kahn ${ }^{* * *}$ \\ Colaborador del Centro de Estudios Judaicos, \\ Universidad de Chile \\ ORCID: 0000-0001-7356-6679
}

\author{
Nelson Marín Alarcón ${ }^{* * * * *}$ \\ Centro de Estudios Judaicos, Universidad de Chile \\ ORCID: 0000-0003-4579-0336
}

\section{Resumen}

El así llamado estallido social que comenzó en Chile el día 18 de octubre de 2019, se ha vuelto un caso de excepcional interés para diversas disciplinas de las ciencias sociales y humanidades. No obstante, en el consiguiente debate público que el acontecimiento ha producido, también han estado involucradas instituciones evangélicas interpretando las problemáticas que el estallido social ha visibilizado. Este trabajo exploratorio aborda la relación entre religión, política y cambio social en un escenario de deterioro de la confianza en las instituciones religiosas en el Chile de posdictadura. A través de la revisión de las diversas interpretaciones que se han hecho del estallido en el debate público, se busca analizar discursivamente la recepción de este fenómeno social en 
actores evangélicos. En este sentido, la presente investigación se propone analizar el modo en que las agrupaciones evangélicas construyen espacios de visibilización y reconocimiento público en un contexto de crisis de la democracia.

Palabras clave: estallido social, crisis, desconfianza, religión, esfera pública.

\begin{abstract}
In the past few years, Chile has developed a series of actions to ensure the quality of teacher training, including the implementation of mandatory accreditation processes. Teacher training programs for religion teachers are no exception. However, as of 2019, only six institutions had secured national certification. These accreditation processes impact aspects such as the curricular architecture of training offerings. This research uses a qualitative-descriptive approach to study these six institutions, focusing on the analysis of graduate profiles in the context of fundamental teaching by the Catholic church on the role of religious education in the education system. The findings generated show that while the profiles tend to be organized based on certain focus areas shared by the programs, the types of learning refer to a heterogeneous professional identity. This in turn reflects a persistent lack of definition of the relationship of that pedagogical activity with the meaning of the Christian and Ecclesiastic presence amid a pluralistic cultural context that is increasingly reactive to traditional religious institutional structures in general.
\end{abstract}

Keywords: initial teacher training, religious studies teacher, graduate profile, professional challenges, cultural challenges.

\title{
Introducción
}

Hasta hace unos años, el paradigma secularizador hegemónico sugería que instituciones y actores religiosos tendrían una paulatina disminución de 
injerencia en los asuntos públicos y/o privados de las sociedades modernas. Si bien, en algunas sociedades esta idea ha tenido un correlato -pensemos, por ejemplo, en Europa Occidental-, lo cierto es que en otras partes del mundo resulta insuficiente o inapropiado para explicar la compleja relación entre religión y sociedad - Norteamérica, el mundo árabe, etc. Dichas deficiencias teóricas y prácticas han llevado a un número creciente de investigadores a explorar modos alternativos de pensar las relaciones entre religión, política y sociedad en contextos en los que la idea tradicional de la secularización no es satisfactoria.

Las religiones y sus consecuentes instituciones no solo permanecen activas en diversas sociedades, sino también han logrado expandir sus feligresías y capturar nuevas posiciones de influencia pública en algunos casos. $\mathrm{Si}$ bien las tasas de creyentes siguen sugiriendo una amplia aceptación social de las religiones, ¿qué ocurre cuando comienzan procesos intensos de pérdida de confianza? En el caso particular de Chile es un hecho verificable que la credibilidad de dichas instituciones ha disminuido debido a escándalos de índole moral y administrativa, especialmente, aunque poco se sabe aún sobre cómo aquella desconfianza se relaciona con la forma en que dichas religiones se aproximan a los problemas relevantes para la ciudadanía.

Así, en un Chile que ha experimentado importantes procesos de democratización y modernización en las últimas décadas, encontramos una doble tendencia en la que, al tiempo que las religiones han adquirido una renovada notoriedad pública, asimismo han experimentado una creciente crítica desde sus propios creyentes y la población en general. El estallido social que tuvo lugar el día 18 de octubre de 2019 encuentra a su paso no solo el desarrollo del país -que en visiones más o menos optimistas se ha visto fuertemente afectado-, sino también instituciones religiosas muy cuestionadas que intentan articular posiciones frente a la crisis. En este contexto es posible preguntarse ¿cómo intentan las instituciones evangélicas recuperar la confianza que han perdido? ¿Cómo estas instituciones aprovechan la coyuntura del 18 de 
octubre para recuperar la confianza ciudadana? ¿Qué estrategias y discursos utilizan?

Los siguientes apartados tienen por propósito examinar la recepción de las consecuencias del 18 de octubre chileno en instituciones evangélicas mediante una revisión de la discusión sobre religión y esfera pública, así como proponer un análisis de la situación actual de pérdida de confianza de las instituciones religiosas en Chile.

\section{Metodología}

La cercanía contextual con el acontecimiento del 18 de octubre hace todavía difícil desplegar una investigación comprehensiva que permita señalar con mayor detalle la magnitud de su impacto en el ámbito evangélico. De aquí que realizar una investigación de orden sociológico sea todavía un desafío pendiente. Sin embargo, pasados algunos meses ya es posible notar que ha habido una creciente producción discursiva desde individuos, organizaciones paraeclesiales e instituciones religiosas, la cual puede ser analizada sistemáticamente.

En vista de lo anterior, este trabajo elabora una introducción al fenómeno de la recepción del 18 de octubre en el ámbito evangélico tomando herramientas del campo de estudio del Análisis del Discurso (AD). Para ello, resulta necesario precisar con qué tipo de material se trabajará y por qué. Como ya se señaló, la cercanía contextual todavía no permite obtener una imagen pormenorizada de los discursos circulantes. A la vez, las formas de comunicar discursivamente son de gran diversidad. Por estas dos razones, se han seleccionado específicamente tres discursos de carácter institucional emitidos por iglesias y/o por representantes de organizaciones religiosas evangélicas, cuyo género es el de la carta pública. Así, se trata de discursos de cierta representatividad, que cumplen con un cierto estándar de formalidad y que resultan ejemplares para observar los contornos generales del posicionamiento evangélico respecto a la propuesta de una nueva Constitución, surgida a partir 
del 18 de octubre de 2019. Dichos textos han sido escogidos tanto por representar dos posiciones antagónicas (el Apruebo y el Rechazo a la nueva Constitución), como también porque pueden inscribirse dentro de una diferenciación más amplia que responde a la histórica separación que ha habido entre evangélicos ecuménicos y fundamentalistas desde tiempos del régimen militar, los unos en oposición y los otros en favor de dicho régimen (Sepúlveda, 1999).

Entre los presupuestos teóricos del AD, se encuentra el hecho de que tras todo discurso existe una intencionalidad comunicativa (Cortés y Camacho, 2003); esto, porque el discurso no es lenguaje en abstracto, sino situado contextualmente. Tiene, por tanto, una intencionalidad social porque es una práctica social (Fairclough, 1992). Por lo anterior, el AD asume que todo discurso tiene una estructura y que esa estructura está orientada a fines comunicativos y, en suma, sociales. En tal sentido, el hecho de que los emisores hayan seleccionado el formato "carta" o "declaración" públicas, un lenguaje formal, institucional, y una cierta estructura de redacción, no es accidental. En otras palabras, la selección de este modo de comunicación y en este contexto señala claramente la búsqueda de un posicionamiento en la esfera pública. Este mecanismo ha sido usado históricamente por los evangélicos, en especial para dar apoyo u oponerse al régimen militar. Por lo tanto, puede decirse que los actores de estos documentos, aunque enfrentan nuevos contextos, siguen manteniendo una estrategia tradicional de posicionamiento público. Un gesto de modernización puede ser el hecho de que se emitan vía internet y redes sociales, pero, con todo, el género sigue manteniéndose. Así, entonces, ¿cuál es el propósito tras estos textos? Mediante un análisis comparado de las tres declaraciones, se esboza una respuesta a esta cuestión.

Cabe señalar un último aspecto. Todo discurso tiene un contexto de situación y un contexto de cultura (Eggins, 2002). El primero es más inmediato, y en este caso, responde a los acontecimientos relacionados con el 18 de octubre. Sin embargo, el contexto de cultura está relacionado con la serie de condiciones que aportan propósito y significado a la acción discursiva. En este 
sentido, antes de pasar al análisis, se indagará primero en el contexto de cultura relativo a las instituciones religiosas en Chile, para de esta manera explicar los documentos seleccionados con mayor robustez.

\section{Religión, política y cambio social}

Aunque debatida, corregida y refutada en múltiples sentidos, la relación entre religión y política sigue siendo comprendida bajo los supuestos y principios de las llamadas teorías de la secularización. La secularización del Estado, la política o la sociedad en su conjunto sigue siendo un elemento central en la argumentación de quienes se oponen o ven con sospecha los persistentes intentos de agentes religiosos por influir en materias de interés colectivo. Esto, que podría solo ser parte del repertorio cotidiano de políticos y ciudadanos interesados en discusiones públicas, también se refleja en las omisiones y complicaciones que han tenido los analistas políticos al momento de determinar la influencia específica que poseen los actores religiosos, tanto en la promoción de determinadas agendas públicas, como en el comportamiento electoral de los ciudadanos.

Las recientes investigaciones y debates en torno al "voto evangélico", así como la articulación de instituciones religiosas a través de la sociedad civil en la defensa de materias valóricas consideradas prioritarias desde un punto de vista religioso, son algunos de los ejemplos más característicos de esta tensión entre una forma tradicional de concebir la política y las formas religiosas que en ocasiones adquiere. La actual situación de crisis política del país presenta una oportunidad única para explorar estos límites teóricos y prácticos en cuanto al modo en que los especialistas han tendido a pensar la relación entre religión, política y el espacio público.

Siguiendo a Casanova (1994), es posible afirmar que las teorías de la secularización se encuentran entre las pocas construcciones teóricas que han adquirido un estatus paradigmático dentro de las ciencias sociales. Salvo notables excepciones, la secularización cruza de manera general a todos los 
fundadores y escuelas de pensamiento que sostenían el paso radical de lo religioso a lo secular como característica central de la modernidad. En palabras de Martin: "Secularization was made part of a powerful social and historical narrative of what had once been and now ceasing to be" ("La secularización se hizo parte de una ponderosa narrativa social e histórica sobre lo que una vez había sido y ahora dejaba de ser" [traducción de los autores], Martin, 2005, p. 18).

Dependiendo de la disciplina, estas narrativas engloban procesos de transformación profunda desde el nivel cognitivo e individual hasta el cultural y social. Aunque los intentos de clasificar estas transformaciones siguen siendo parte del quehacer de muchos estudiosos de la religión en la actualidad, Casanova (1994) afirma que las teorías de la secularización se han articulado en torno a tres ideas generales: la desaparición de la religión, la privatización de la religión y la diferenciación funcional de la religión respecto de otras esferas sociales. Cada uno de estos supuestos plantea una forma de relación entre religión y política que merece una exploración más profunda.

Más allá de constatar la evidente persistencia de lo religioso en las sociedades modernas, para efectos políticos son interesantes aquellas teorías de la secularización que pronosticaban la privatización de la religión. Relacionada con las teorías de la diferenciación funcional de la religión, la privatización religiosa planteaba que en la medida que la religión perdiera su hegemonía en la construcción significativa del mundo de los individuos, lo que Berger (1990) llamaba cosmization, las instituciones religiosas se volverían crecientemente marginales e irrelevantes en el funcionamiento del mundo moderno. De acuerdo con Luckmann (1967), dicha privatización llegaría a un punto tal que incluso quedaría cada vez más restringida al ámbito privado y la conciencia de los creyentes. No obstante, nuevamente la evidencia empírica demuestra que las religiones no solo no han abandonado sus pretensiones colectivas, sino que exhiben gran proactividad en el ámbito público. Como menciona Calhoun: "the prominence of religion still has the capacity to startle secular thinkers who thought it was clear destined to fade in the face of enlightenment and 
modernity" "'La prominencia de la religión aún tiene la capacidad de asustar a los pensadores seculares que pensaban que evidentemente esta estaba destinada a desaparecer frente a la Ilustración y la modernidad" [traducción de los autores], 2011, p. 118).

Casanova (1994) afirma que este proceso de "des-privatización" se ha dado en dos sentidos. La religión se ha hecho pública por medio de la contestación moral en el ámbito político, así como también ha ganado publicidad de parte de gobernantes, políticos y especialistas. Desde la segunda mitad del siglo XX (Casanova enfatiza particularmente la década de 1980), parte importante de las transformaciones y conflictos políticos globales han tenido un componente religioso central (la lucha por los derechos civiles en Estados Unidos, la Revolución islámica en Irán, el rol de la Iglesia católica en los movimientos revolucionarios en América Latina, entre muchos otros ejemplos). Más aún, problemas centrales como el terrorismo y la violencia política contemporánea son legitimados moralmente, ritualizados e imaginados en términos religiosos (Juergensmeyer, 2001; Pratt, 2018).

Finalmente, la secularización como diferenciación de esferas es probablemente la versión con mayor aceptación actual, aunque no sin reparos y precisiones. Sostenida en principios similares a la idea de privatización religiosa, la diferenciación funcional apunta a que, con el desarrollo de la modernidad, esferas como la religión, la política, la economía, las artes, etc. adquirirían niveles de autonomía, tanto en su definición como en su funcionamiento. En la práctica, esto implica el fin de visiones de mundo totalizantes (el "dosel sagrado" de la religión según Berger [1990]), liberando así cada ámbito de la vida a sus propias reglas y racionalidades. En el ámbito político, esta diferenciación se expresaría habitualmente en la tendencia moderna hacia la separación entre Iglesia y Estado, aunque el objetivo fundamental es establecer la neutralidad del Estado frente al pluralismo religioso interno como condición necesaria para la libertad religiosa, la igualdad religiosa y la fraternidad religiosa (Taylor, 2011). 
Sin embargo, esta autonomía de la religión respecto de la política ha sido muchas veces asumida como normativa al momento de excluir la religión del ámbito público. Esto pasaría, tanto por una concepción de lo político que tiende a homologar lo público con lo estatal y la política formal, así como por entender las fronteras de estos campos como impermeables y no negociables. Sobre este último punto, Casanova (2012) afirma que si bien durante mucho tiempo se asumió que la separación rígida entre "religión" y "política", incluso entre "iglesia" y "Estado", era un requisito central para el desarrollo de la democracia, la tendencia actual es a ver ambos dominios como interrelacionados y en constante influencia mutua. Tocqueville fue uno de los pocos (si no el único) en percibir estas relaciones de interdependencia entre los asuntos religiosos (creencias, conflictos interdenominacionales, etc.) y la configuración y el ejercicio de la democracia norteamericana (Casanova, 2012).

En este sentido, la crítica a la universalización de formas históricamente contingentes de modernización y secularización -sin considerar las formas particulares de relación entre iglesias, Estados y naciones- estaría a la base de las recientes críticas a las formas políticas del paradigma de la secularización. Para el caso latinoamericano, extensible además al chileno, implica pensar procesos de modernidad más allá de la simple privatización, desinstitucionalización o separación. Como menciona Levine, "the question is also not well addressed in terms of 'resurgence' or 'politization' of religion. Religion has never really been absent from politics and society in Latin America" ("La pregunta es además no bien formulada en términos de resurgencia o politización de la religión. La religión nunca ha estado realmente ausente de la política y la sociedad en América Latina" [traducción de los autores], Levine, 2012, p. 54).

Morello y otros autores prefieren hablar para América Latina de una "modernidad encantada", no solo para marcar distancia con las reglas o excepcionalismos europeos y norteamericanos, sino también para establecer regímenes donde, aunque las autoridades religiosas ejercen menos influencia que antes, la religión es todavía una fuente de legitimación en esferas seculares 
de valores como la política (Morello, Romero, Rabbia y Da Costa, 2017). De esta forma, aunque es posible percibir una relativa pérdida de control de los tradicionales instituciones y líderes religiosos (Bruce, 2010), en la práctica los individuos siguen adhiriendo a valores religiosos a la vez que demandan mayor independencia, autoexpresión y libertad personal (Inglehart, 2009). Más allá de las pretensiones de universalidad, la secularización debe ser leída desde la particularidad de las sociedades, grupos e individuos que la experimentan (Ammerman, 1994), en un contexto de interacción constante entre agentes, discursos y saberes a nivel local y global (Campos, 2007).

Aunque las religiones pueden comprometerse y participar en diferentes formas e intensidades, Casanova afirma que una religión pública "es aquella que asume o intenta asumir un carácter, función o rol público” (2012, p. 123). La naturaleza de lo "público" y su relación particular ha adquirido diferentes énfasis dependiendo de cuan abstracto se considere este espacio o esfera pública. Mientras para algunos el espacio público en las sociedades democráticas se define en términos de las racionalidades que deliberan sobre temas de interés común, siendo el principal conflicto determinar cómo los lenguajes y argumentos religiosos se ajustan a los parámetros de la racionalidad pública secular (Habermas, 2011; Rawls, 1997), otros piensan la relación entre lo religioso y lo público en términos de los arreglos institucionales o sociales que configuran ciudadanos imposibilitados de desprenderse de sus profundos compromisos morales (Neuhaus, 1984).

Casanova (2012) propone una distinción analítica basada en tres dimensiones del sistema de gobierno (Estado, política y sociedad civil) para distinguir y localizar formas concretas de religión pública. Mientras las religiones públicas estatales (teocracias) irían en retroceso en el mundo occidental, quedando sujetas a arreglos puntuales en algunos lugares (Inglaterra, Argentina, etc.), las religiones públicas a nivel político se seguirían expresando a través de mecanismos como los partidos (la Democracia Cristiana en Chile, por ejemplo). No obstante, sería a nivel de la sociedad civil donde las religiones públicas actuales encontrarían mayor espacio de crecimiento por 
medio de movimientos sociales y organizaciones de base. Esto generaría importantes formas de rearticulación entre religión y política, especialmente en lugares que han experimentado procesos de democratización, expansión de la sociedad civil y pluralismo, como ha ocurrido en América Latina en las últimas décadas (Levine, 2012). Para el caso regional, Semán (2013) sostiene que a diferencia del catolicismo, que forjó su sitial de poder en íntima relación con la élite, las agrupaciones evangélicas “[...] en especial el pentecostalismo, han debido hacerse endógenos [...] y salir de una situación periférica para aproximarse al centro todo lo que es posible” (Semán, 2013, p. 74). Analizar las tensiones que estos antiguos y nuevos actores e ideas religiosas imponen en los emergentes escenarios de crisis política, es parte de lo que este artículo busca explorar.

Las maneras en cómo los actores e instituciones religiosas se aproximan a los procesos de crisis social pueden ser profundamente diferentes. En primer lugar, la discusión sobre el rol que poseen las religiones en la reproducción o cambio social ha sido tan constante y transversal como las propias teorías de la secularización. Siguiendo a Lincoln (2003), estas teorías han oscilado entre dos formas de reduccionismo. En primer lugar, aquellas teorías "románticas" que idealizan la religión en sus efectos y funciones positivas para la integración social, la conformación de las instituciones sociales, la provisión de un set coherente de valores, y los significados trascendentes que ofrecen a los individuos (Durkheim es el ejemplo por excelencia en este sentido). Por otra parte, están aquellas teorías "materialistas" que reducen la religión a una función ideológica a favor de los grupos dominantes o privilegiados de la sociedad (los teóricos de la sospecha-Marx, Nietzsche y Freud- representan claramente esta postura). Aunque Lincoln admite que ambos extremos pueden no estar del todo equivocados, siendo las funciones de legitimación social parte de los roles que cumplen comúnmente las religiones, la reducción a estas funciones específicas, así como el carácter parasitario asignado a la religión respecto de otras variables consideradas más importantes (la política y la 
economía usualmente), representan un sesgo que no permite evaluar las complejas interdependencias que se construyen entre religión y política.

Adicionalmente, el carácter reactivo asignado por lo general a la religión ha generado cierto rechazo por parte de aquellos sectores y fuerzas políticas que promueven procesos de transformación, así como también la omisión de aquellas formas religiosas que construyen formas de resistencias y proyectos de futuro específicos. En este sentido, Lincoln (2003) distingue entre "religiones de statu quo", "religiones de resistencia" y "religiones de revolución". Mientras las primeras contribuyen a la estabilidad de una comunidad política o social (las iglesias nacionales, por ejemplo), las religiones de resistencias desafían el orden ideológico dominante por medio de mecanismos heterodoxos (ascéticos libertarios, orgiásticos, nihilistas, esotéricos, pacifistas, etc.). En otra vereda, las religiones de revolución, las cuales persiguen una transformación efectiva en las condiciones sociales (orden económico, jurídico, militar, nutricional, educacional, etc.), actúan en correspondencia con intereses y mecanismos definidos más allá de lo considerado estrictamente religioso. En cualquier caso,

religious movements can provide their members with important religious resources to help them make sense of and develop strategies for action in response to the challenges of everyday life. While such small steps may not produce the next great social revolution, they are nonetheless important, insofar as they constitute what Jelin (...) refers to as an "infrapolitics of the voiceless", through which dignity and a sense of community are constructed. (Los movimientos religiosos pueden proveer a sus miembros de importantes recursos religiosos para ayudar a hacer sentido y desarrollar estrategias para la acción en respuesta a los desafíos de la vida cotidiana. Mientras aquellos pequeños pasos podrían no producir la próxima gran revolución, son, sin embargo, importantes en tanto constituyen lo que Jelin refiere como la "infrapolítica de los sin voces", a través de la cual la dignidad y el sentido de comunidad son construidos. ([Traducción de los autores], Peterson, Vásquez y Williams, 2001, p. 16). 
Finalmente, comprender las relaciones entre religión y política más allá de la secularización y las definiciones rígidas sobre lo político y lo público, abre posibilidades de observar las maneras en cómo los agentes religiosos procesan el cambio y las crisis sociales desde sus cosmovisiones y estructuras específicas. En algunos casos, la religión proporciona narrativas que permiten dar luces sobre acontecimientos políticos que perturban la vida de una comunidad, otorgando un sentido trascendente a la identidad colectiva, motivando a la acción y permitiendo visualizar horizontes posibles o utópicos (Peterson, 1996; Watanabe, 2009). En palabras de Rubin, Smilde y Junge: “As citizenships constructed in zones of crisis, religion shapes the ways people understand themselves, the trajectories of collective mobilization, and individual and group survival strategies" ("Como ciudadanías construidas en zonas de crisis, la religión modela las formas en que la gente se entiende a sí misma, las trayectorias de movilización colectiva, y las estrategias de sobrevivencia individual y grupal" [traducción de los autores], 2014, p. 8). Las respuestas a estas situaciones de crisis cubren un amplio rango de posibilidades, desde formas de articulación abiertamente políticas (movimientos populares de tipo milenaristas, colectivos políticos-religiosos, escuelas de formación ciudadana al interior las iglesias, etc.) hasta formas cotidianas de refugio y solidaridad frente a la incertidumbre y la injusticia social. Tal como mencionan Levine y Stoll (1995), en América Latina la religión es central en la conformación de constelaciones de sentido, habilidades sociales y experiencias de cooperación (capital social, en otros términos) que terminan por alterar el campo político, fomentando la creación de confianzas y compromiso cívico. En las siguientes páginas exploraremos las reacciones discursivas que distintos actores religiosos han logrado articular en el caso de la crisis social vivida en Chile desde el pasado 18 de octubre. 


\section{La desconfianza como factor del debilitamiento de la democracia y su impacto en las instituciones eclesiales}

La participación de agentes religiosos evangélicos en política contingente responde a una realidad en gran parte de Latinoamérica. La incidencia en el rechazo al primer intento de acuerdo por la paz en Colombia, el apoyo a la candidatura de Jair Bolsonaro en Brasil, su incorporación al gobierno de Andrés Manuel López Obrador en México, entre otros hechos, dan cuenta de su visibilización en la arena política regional. No obstante, la crisis de confianza en las instituciones, y su consecuencia directa en política, reflejada en el debilitamiento de la democracia, nos invita a analizar el papel que juegan las agrupaciones religiosas evangélicas en dicho escenario.

En un contexto más amplio, el informe del Pew Research Center (2014), en uno de sus apartados, indaga en la relación de religión y política en América latina consultando por las preferencias de los encuestados para la resolución de problemáticas en sus respectivos países. En términos generales, se inclinan por la opción "una forma democrática de gobierno" en desmedro de "un líder con mano fuerte" (eufemismo para dar cuenta de un régimen autoritario). No obstante, llama la atención el alto apoyo que posee esta última opción en países como El Salvador, (45\%), República Dominicana (47\%), Perú (44\%), Paraguay (43\%), Brasil (39\%), Honduras (38\%). Un ejemplo más de la crisis de confianza en los gobernantes, los partidos políticos tradicionales y el sistema democrático en la región.

Los vínculos de las agrupaciones evangélicas con la política, en el contexto chileno, también poseen momentos de tensión, en los que se confrontan las creencias religiosas con otros modelos o filosofías de vida. Los denominados temas valóricos (Sandoval, 2018) constituyen uno de ellos: el proyecto de despenalización del aborto, aquel relacionado con el matrimonio igualitario, y la discusión sobre la ley de identidad de género, se constituyen en espacios de debate en que ciertas agrupaciones religiosas (evangélicas y 
católicas) sostienen su rechazo en la superioridad moral que les provee su sistema de creencias.

Los hechos descritos precedentemente ayudan a comprender el escenario de conflicto, desconfianza y crisis de las instituciones, siendo aquellas de carácter religiosas protagonistas de los hechos acaecidos durante las últimas décadas, y que se expresan en la crisis social y política más aguda que ha vivido Chile desde el quiebre democrático en 1973.

Las manifestaciones acaecidas en Chile, detonadas por el alza del pasaje del metro capitalino durante el mes de octubre de 2019, permiten dar cuenta, a nuestro juicio, no solo de una demanda concreta, sino más bien de un malestar acumulado que expresa injusticias, desigualdades, privilegios, angustias, desconfianzas, etc. La escalada de sentidas demandas reflejadas en una mejora en el sistema de previsión social, sueldos éticos, salud digna, educación gratuita y de calidad, entre otras, han ido acompañadas del anhelo de mayor participación en las decisiones políticas que construyen el Chile actual, así como de una profunda desconfianza hacia todas las instituciones y sus líderes (políticos, empresariales, religiosos, etc.).

La crisis social y política que vive actualmente Chile se manifestó con fuerza en lo que se ha denominado "estallido social". No obstante, dicha crisis encuentra antecedentes en el deterioro de las instituciones de manera generalizada desde hace décadas en el país. Los análisis de académicos, políticos, economistas, periodistas, entre otros, han inundado los espacios informativos otorgando múltiples hipótesis para explicar la crisis, desde aquellos que la "vieron venir" hasta quienes se sienten "sorprendidos" por los hechos ocurridos. Sin embargo, el volumen de información diagnóstica acumulada es múltiple, desde los completos informes elaborados por el PNUD en Chile (2002), hasta textos como el del sociólogo Tomás Moulian (1998, 2002), que han descrito a una población que desde mediados de la década de 1990 se caracteriza por lógicas de consumo exacerbado, pérdida del tejido social, individualismo, endeudamiento, etc., y que han permitido vislumbrar el malestar que se estaba anidando. 
Si bien la clase política, representada en instituciones y personas, es de las más cuestionadas por la sociedad, el progresivo detrimento de las iglesias llama la atención considerando la alta valoración que poseían a inicios de la restauración de la democracia en 1990. Es probable que la desafección o alejamiento de las instituciones eclesiales por parte de los sujetos se enmarque en los cambios socioculturales que fueron desarrollándose en un Chile que se abría al mundo en el plano económico, con una masificación paulatina de las nuevas tecnologías de la información, mayor nivel de cobertura educacional (Fediakova y Parker, 2009), así como con un cuestionamiento hacia las iglesias y sus liderazgos por un marcado tono moralista y censurador, a inicios de los noventa, que restringía libertades luego de un largo período de opresión (Bahamondes, 2017).

Rechazo al divorcio, oposición a la implementación de las jornadas de educación sexual en los colegios, cuestionamientos a la entrega de la píldora del día después en los servicios públicos de salud, discusiones respecto al estatus del matrimonio y composición de la familia, presión para evitar legislar respecto al aborto, entre otras materias, fueron paulatinamente configurando un modelo de representación social de las iglesias mayoritarias en Chile (católica y evangélica) como entidades conservadoras y con una baja empatía con los problemas y demandas de la ciudadanía. Frases como "la ley de Dios está por sobre la ley de los hombres" se transformaron en una de las armas predilectas de los sectores más conservadores de estas iglesias, viendo como una amenaza los cambios que la sociedad chilena comenzaba a manifestar y que se traducían en demandas sociales.

Los hechos descritos como antecedentes permiten ir retratado no solo la distancia que los chilenos comenzaban a marcar con mayor fuerza hacia las iglesias, sino que también a cuestionarse la forma de vivir la religión, ya no solo al amparo de una iglesia, templo o centro de culto. Junto con ello, las críticas hacia el ejercicio del poder, sus liderazgos y estructuras fueron dando forma a un cuestionamiento generalizado a las iglesias locales. 
El repliegue hacia los sectores más acomodados y la falta de cobertura de la Iglesia católica en las poblaciones y villas carenciadas, junto a la gran capacidad de autogestión y cercanía del "mundo evangélico" hacia dicho segmento, no solo fueron reconfigurando el mapa religioso de Chile, sino que también implicó un fraccionamiento de la feligresía de manera más evidente. Se hablaba de "religiones de pobres" o "catolicismo de élite", por citar algunos apelativos, los que daban cuenta de los imaginarios en construcción de una religión móvil en un país que mostraba transformaciones en diversas aristas (mejoría en los índices de cobertura educacional, disminución de la pobreza, mayor cobertura de servicios básicos, etc.).

Sin embargo, fue a partir del año 2000 que se produjo el mayor deterioro de la Iglesia católica chilena, a raíz de una seguidilla de denuncias por abuso sexual que involucraban a importantes líderes religiosos cercanos a la élite local. El párroco Fernando Karadima; el presbítero John O'Reilly de los Legionarios de Cristo; Óscar Muñoz, el excanciller del Arzobispado de Santiago; Francisco José Cox, arzobispo emérito de La Serena; el jesuita Renato Poblete, entre otros, fueron actores que no solo se trasformaron en casos judiciales y eclesiásticos emblemáticos. En efecto, sus casos develaron la protección y empatía de ciertos sectores de la élite y de la propia jerarquía de la iglesia local a los religiosos denunciados. De esta forma, las víctimas, en muchos casos fueron cuestionadas y estigmatizadas, siendo los perpetradores de los delitos quienes contaron con el respaldo y apoyo público de sus propias instituciones.

La lógica de la transfiguración de los relatos dio pie a una proliferación de eufemismos y ocultamiento de información en diversas instituciones (eclesiales, empresariales, políticas, policiales). Poco se hablaba de delitos y mucho de faltas o pecados. De esta forma, "[1]as faltas, desde violación a menores, hasta desfalcos, se tratan como asuntos internos: la ropa sucia se lava en la parroquia, el cuartel o el retén" (Matamala, 2019, p. 48).

Sin lugar a dudas, este tipo de hechos no solo contribuyeron a profundizar el descontento hacia una iglesia que no habría considerado en su 
mérito las denuncias de las víctimas, y que no se agotaba en hechos aislados, sino que daba cuenta de una estructura de poder capaz de abusar de la conciencia y ejercer el poder que poseía producto del estatus alcanzado durante siglos. En palabras de Mayol (2019):

El ciclo de crisis de 2011 a 2019 fue destruyendo los intermediarios. La crisis de la Iglesia católica primero y evangélica después deja a los fieles simplemente frente a su propia fe o, en el mejor de los casos, frente a Dios. (Mayol, 2019, p. 78).

La confianza, como valor y signo distintivo de la Iglesia católica, comenzaba a ser parte del pasado, y sus cifras de adhesión y confianza se desplomaban en cada encuesta de opinión, como queda de manifiesto en los estudios realizados por el ciclo de Encuestas Bicentenario (PUC, 2019). Si bien el año 2006 la adhesión al catolicismo alcazaba el 70\%, para el año 2019 las cifras se desplomaban al 45\%. En cuanto a los niveles de confianza, el "Estudio Nacional de Opinión Pública N84" (CEP, 2019) muestra una abrupta caída en dicho indicador, tanto para la Iglesia católica como para la evangélica. La primera, el año 2009 contaba con un 50\% de confianza, porcentaje que en diciembre de 2019 alcanzó a solo el 14\%, mientras que la Iglesia evangélica en el mismo horizonte temporal mostró una caída del 32\% al $17 \%$.

En relación con el "mundo evangélico", su estructura pluricelular, divisionismo y heterogeneidad (Bahamondes, 9 de marzo de 2020; Rivera, 2014) no permite realizar generalizaciones. Sin embargo, sus disputas constantes entre distintas denominaciones por la búsqueda de protagonismo, poder y dinero han erosionado la confianza de la sociedad. Escándalos de corrupción, falta de transparencia en su contabilidad, dudosa conducta moral de algunos de sus líderes con alta exposición pública, así como un discurso agresivo hacia la diversidad sexual y temáticas de género, fueron alimentando la desconfianza y el descrédito de una de las religiones de mayor crecimiento en el Chile actual.

En definitiva, las iglesias han perdido paulatinamente, a nuestro juicio, la hegemonía no solo de lo religioso, sino también del sentido de comunidad 
(Berger y Luckmann, 1997) que parecían entregar a la sociedad chilena, resultando lejanos aquellos tiempos donde su protagonismo ante las problemáticas y conflictos sociales permitía encontrar entre sus liderazgos un interlocutor válido ante la ciudadanía (Reforma agraria, violación de los derechos humanos, restauración de la democracia, etc.). En este sentido, Mayol (2019) advierte:

No hay que desmerecer la relevancia de la obligada ausencia de la Iglesia católica como posible actor que pudiera dotar de legitimidad al sistema político en medio del ciclo de crisis. La verdad es que la política nacional se había acostumbrado, tanto en dictadura como después de ella, a tener un rol activo de la Iglesia católica, normalmente con fines conservadores, pero a veces para informar al sistema político que no podía quedarse atrás en ciertos requerimientos sociales. (Mayol, 2019, p. 153).

Si a comienzos de la democracia las iglesias fueron un actor clave en el proceso de restauración del país, resultan lejanos aquellos tiempos de protagonismo, liderazgo y búsqueda de paz, pues hoy el silencio o la tibieza de su pronunciamiento ante la crisis social y política que vive el país los sitúan como actores secundarios. La pérdida de exclusividad de "institución en crisis" hoy se ha masificado hacia todas las entidades en el país, no obstante, su participación en la búsqueda de soluciones solo se ha remitido a tibias y acotadas declaraciones públicas llamando a la paz.

En palabras del jesuita Felipe Berríos:

...uno espera que los pastores sean pastores y que sufran con el sufrimiento de la gente, se alegren con la alegría de ellos. Entonces, ante estas situaciones que estamos viviendo en Chile, tan profundas, el silencio de los distintos obispos nos desconcierta (Felipe Berríos sobre el estallido social..., 15 de febrero de 2020).

En definitiva, la gran cantidad de personas movilizadas a través de todo el país desde el inicio del estallido social el 18 de octubre de 2019 no solo ha remecido los cimientos del actual gobierno del Presidente Sebastián Piñera y todas las instituciones del país, sino que también busca poner fin a las lógicas 
instaladas desde la restauración de la democracia, que le decían a la población que los avances en diversas materias de interés social solo se podrían lograr "en la medida de lo posible" (en el decir del Presidente Patricio Aylwin), perpetuando así la estructura social, económica y política de la dictadura cívicomilitar liderada por el general Augusto Pinochet. Asimismo, las personas movilizadas buscan repensar las lógicas bajo las cuales se ejerce el poder en todas las instituciones que regulan la vida cotidiana de los chilenos. En este sentido, cabe atender a lo expresado por Mallimaci (2013), quien propone:

Insistir en el reconocimiento de la ciudadanía religiosa, es decir, donde no haya privilegios ni superioridades y donde todas las personas sean iguales en sus convicciones y creencias, y la importancia de valorar y reconocer que cada uno y cada una puedan elegir el tipo de vida, pareja, cuerpo, creencia, partido político, deseo o género que más le satisfaga... (2013, p. 21).

Un último aspecto que importa señalar, es la variedad de perspectivas que se han ido produciendo respecto al 18 de octubre. Reconocidas las limitaciones propias de dichos análisis, dado su carácter contingente, al menos ofrecen una idea de cómo se está leyendo y narrando el desarrollo de los acontecimientos. Mediante un repaso rápido de estas narrativas, será posible también observar cómo los casos de instituciones religiosas que hemos tomado de ejemplo se relacionan con estos relatos dominantes.

Como es esperable de eventos de naturaleza nacional, el así llamado estallido social del 18 de octubre en Chile no fue indiferente para ningún sector. Es por ello que tampoco sus interpretaciones han sido iguales ni similares. Hay perspectivas desde los más variados sectores, y si bien la prensa y las redes sociales han sido los espacios de discusión más populares, también ha habido en simultáneo una producción bibliográfica, principalmente ensayística, que desde temprano comenzó a aparecer. Al presente, intelectuales provenientes de las más diversas posiciones y disciplinas han escrito libros referidos al acontecimiento. Dado que en estas obras, por el hecho de ser fruto de un trabajo de pensamiento más dilatado, despliegan una reflexión más sistemática que la 
que permitiría el espacio de una columna, resulta conveniente referirse a algunas de ellas para perfilar brevemente ciertos rasgos del debate.

En general, podría decirse que hay dos grandes narrativas. Como se enunció anteriormente, hay un relato que sostiene que lo acontecido el 18 de octubre fue un "estallido social". Esta categoría implica la presuposición de que lo ocurrido emerge como una manifestación desde la sociedad civil y, por lo tanto, no propiamente desde el campo político.

En la perspectiva de Garcés (2020):

un "estallido social" puede definirse como "un acto multifacético de alteración del orden preestablecido que congrega a diversos actores con sus propias dinámicas, que se sabe de antemano que tiene principio y fin, y que en muchos casos representa una "oportunidad" para hacer justicia por vía práctica". (2020, p. 42).

Visto así, son dos las grandes explicaciones complementarias que pueden darse al fenómeno chileno. Por una parte, se trata de la expresión de un descontento acumulado respecto a desigualdades estructurales y abusos y, por otra, la escisión que ha habido entre la "clase política" -transversal a los partidos- y el "pueblo" (Garcés, 2020, p. 30). De este modo, el estallido chileno obedece enteramente a una expresión de descontento social multisectorial.

No obstante lo anterior, también hay posturas que desafían la narrativa del "estallido". Así, por ejemplo, una narrativa enteramente opuesta es la que sostiene Muñoz (2020), quien propone que lo que ocurrió en Chile fue una “agresión (...) político-delictiva" (2020, p. 27), cuyo fin no era otro que generar “desgobierno". Comentando la terminología ya instalada en los medios de comunicación, Muñoz afirmó: "la violencia, se decía, no era sino un estallido contra la desigualdad. En rigor, la revuelta tenía poco de "social", y era más bien antisocial” (2020, p. 28). El planteamiento de Muñoz sugiere que lo ocurrido el 18 de octubre partió primero como un planificado "ataque terrorista" (2020, p. 26) al Metro, desde luego planificado, que pudo también tener un grado de ayuda de agentes extranjeros (no olvidar que se acusa apoyo venezolano), que luego vino acompañado de una manifestación social -por 
cierto, de gran envergadura- el viernes 25 de octubre. En sus términos, “primero fue la violencia, después el libreto de justificación” (2020, p. 40). Como se menciona a lo largo de todo el libro, el propósito de la agresión político-delictiva, en suma, no fue otro que la desestabilización de las instituciones de la república.

En otro sentido, también hay quienes aceptan la hipótesis del estallido, pero que ven entre sus razones elementos distintos a los mencionados por Garcés (2020). En particular, Herrera (2019) afirma que lo ocurrido el 18 de octubre no se explica simplemente por razones económicas. En efecto, "nunca el país había estado en mejor situación económica que en nuestro tiempo, y ahí están las marchas y el movimiento más grande en décadas” (2019, p. 19). Esta afirmación parece ir en abierto contrapunto con la idea de Garcés (2020), según la cual el 18 de octubre se debe entre otras cosas a las desigualdades preferentemente económicas. Lo que Herrera observa como una causal fundamental de esta "crisis" es un "desajuste grave, profundo entre las pulsiones y anhelos populares, y la institucionalidad política y económica" (2020, p. 13). No se trata aquí de sostener si lo que ocurrió el 18 de octubre fue un "estallido" espontáneo o un "ataque terrorista" planificado, cada cual con su correspondiente explicación. De acuerdo con el autor, lo ocurrido el 18 de octubre no sería solo el resultado de la implementación del modelo neoliberal y sus consecuencias socioeconómicas, como tampoco sería solo un ataque político-delictivo concertado que solo posteriormente adoptó un cariz "social". De lo que se trata en la visión de Herrera es de comprender el 18 en una perspectiva de larga duración, en el marco de la evolución política de Chile y del histórico desajuste que ha habido en la relación entre pueblo y política. La crisis es un resultado de la falta de "comprensión política" que ha caracterizado a las élites. Así, el foco se traslada desde el descontento social al rol desempeñado por las élites gobernantes, de izquierdas y derechas, en la gestión de Chile. 


\section{La recepción evangélica del 18 de octubre}

Tener cierta claridad respecto a los discursos dominantes en relación con lo ocurrido el 18 de octubre es de vital importancia para analizar las reacciones y tomas de posición al interior de la diversa comunidad evangélica en Chile. La razón para ello, desde un punto de vista del discurso, reside en que las ideas formuladas en todo contexto social no pueden separarse del mismo. Esto no implica solamente que el uso del lenguaje en las declaraciones requiere ser comprendido en el marco del acontecimiento nacional particular, sino también que ese propio uso del lenguaje -en una clave identitaria precisamente evangélica para este caso- es deudor del lenguaje que lo circunda y que no proviene de la clave identitaria de la comunidad evangélica. Así, resulta conveniente señalar que los discursos producidos en el marco de los acontecimientos del 18 de octubre son en cierto modo deudores de los relatos dominantes en la discusión pública, tanto en los medios de comunicación como en los distintos actores sociales que dan cuenta del fenómeno. Los relatos dominantes son tomados, reproducidos, reformulados, modificados y descartados.

Lo anterior no debe entenderse como una cierta subordinación del discurso al fenómeno social particular. En términos teóricos existe una relación dialéctica entre práctica discursiva y práctica social. Hay ocasiones, como el 18 de octubre, en que esta última parece imponerse sobre la primera. Pero también hay otras ocasiones en las que la práctica discursiva puede modificar en algún sentido una práctica social y/o su significado (Fairclough, 1992). Así, por ejemplo, mientras que en el caso evangélico ocurre que los diversos sucesos y las prácticas sociales asociadas al 18 de octubre tuvieron como consecuencia la gestación de un discurso propio referido a ello, también ocurre que las prácticas discursivas pueden generar cambios en las prácticas sociales. Dentro del marco del 18 de octubre resulta interesante notar el empleo del significante “dignidad”. Dicho término en el presente ilustra un campo semiótico -no solo discursivo- en disputa. Las prácticas sociales asociadas al 18 de octubre 
llevaron a renombrar la Plaza Italia como Plaza de la Dignidad. Desde luego, el nombre oficial, institucional, sigue siendo el primero, pero el movimiento social ha disputado esa institucionalidad mediante un gesto discursivo $-\mathrm{y}$ político, en cuanto percepción de la polis- que consiste en renombrar. Las convocatorias, que entrañan prácticas sociales, no son ya hechas para la Plaza Italia, sino para la Plaza de la Dignidad. La práctica discursiva modifica la percepción, la interpretación social de lo que significa ese territorio, no solo físico sino simbólico. La práctica social de la marcha, para estos efectos, ya no es comprendida como un apropiarse del lugar ajeno, sino como el habitar lo propio.

El "mundo evangélico" -como se lo suele denominar en un lenguaje corriente- no puede ser analizado del mismo modo que se analizaría a los grupos católicos y la Iglesia católica, debido no solo a su carácter heterogéneo, sino sobre todo a la ausencia de estructura de orden o pluricelularidad. En este sentido específico, el "mundo evangélico" es anárquico, en cuanto que no hay cabeza institucional que sea capaz de aglutinar y representar a todos los sectores. No solo hay una diversidad de iglesias organizadas y denominaciones -que extraen su identidad frecuentemente de su surgimiento histórico y particularidad teológica-, sino que también hay una diversidad de organizaciones que, sin necesariamente adscribir a una teología, denominación o iglesia específica $-y$ sin necesariamente estar compuestas por miembros de una sola de estas orgánicas-, buscan participar de la vida pública e involucrarse en asuntos públicos. Por ello, para examinar la recepción del 18 de octubre y sus consecuencias en el "mundo evangélico" es determinante haber considerado esta pluralidad interna.

La consecuencia probablemente más comentada del 18 de octubre ha sido el "Acuerdo por la paz social y la nueva Constitución", firmado el 15 de noviembre de 2019 de manera casi totalmente transversal por autoridades y representantes de los más diversos sectores políticos. Este hecho fue una apropiación política del hasta entonces acéfalo estallido social, asumiendo así jefes de partidos y congresistas la conducción institucional de las demandas 
sociales. Es en este marco que se encuentran, en particular, interesantes declaraciones que, aunque como se ha dicho, no pueden representar en modo alguno una posición general evangélica, representan al menos dos tomas distintas de posición respecto a la idea de una nueva Constitución en el contexto del acontecimiento del 18 de octubre y, en tal sentido, se alinean de uno u otro modo a las dos grandes narrativas dominantes. Para esto, de entre los diversos textos que han circulado, se ha hecho -sin pretensiones de exhaustividad- una selección de tres declaraciones que analizamos a continuación bajo los criterios mencionados anteriormente en el apartado metodológico.

Un acontecimiento importante respecto a la nueva Constitución en el ámbito evangélico lo marcó la publicación de una declaración pública a la que llamaremos "Declaración de Concepción”, emitida el día 4 de enero de 2020, en la que diversos líderes evangélicos llamaron a votar por el Rechazo a una nueva Constitución. Esta toma de posición pública apareció en diversos medios y fue firmada por una cantidad importante de obispos de diversas iglesias; por presidentes de Consejos pastorales de ciudades y regiones (Los Andes, Talca, Talcahuano, Puerto Montt, entre varios otros); por representantes de ONG evangélicas de interés público como CONFAMILIA, Chile Cristiano, entre otras; y por figuras más mediáticas como el Alto Representante Protocolar de las iglesias evangélicas ante el gobierno de Chile, obispo Jorge Méndez. Esta declaración se alinea así con una profusa campaña impulsada por la derecha, sector político con el que obispos como Jorge Méndez han estado fuertemente vinculados. Esta relación evangélicos-derechas que se observa en el presente, hunde sus raíces hasta los tiempos del régimen militar (Sepúlveda, 1999). El texto está ordenado de manera sencilla en tres puntos que pueden ser organizados temáticamente como solidaridad con la ciudadanía, resistencia al laicismo y conservadurismo político. Todos ellos son, finalmente, argumentos para abogar por la mantención de la Constitución vigente y configuran lo que podríamos denominar una narrativa reformista.

Los líderes evangélicos por el Rechazo no niegan que haya demandas sociales justas, incluso solidarizan con la ciudadanía: 
Compartimos absolutamente las demandas sociales que la ciudadanía ha manifestado en los temas como; mejoras en el sistema previsional, sistema de salud, mejoras en las pensiones, aumentar el ingreso mínimo mensual, terminar con los abusos y delitos de colusión. Sin embargo, para dar respuesta a estas problemáticas no necesitamos una nueva Constitución" ("Declaración de Concepción" cit. en Líderes de iglesias evangélicas en Chile..., 2020, enero).

Así, se produce una disociación. Mientras que el discurso habitual por el Apruebo asocia nueva Constitución con cambios sociales, indicando usualmente con ello que permanecer bajo la Constitución vigente sería una forma de mantener los problemas por los cuales se protesta, los firmantes de la "Declaración de Concepción” elaboran una comprensión según la cual permanecer bajo la Constitución vigente no necesariamente implica mantener las inequidades que el estallido social denuncia. Incluso, se omite aquí el relato de derecha más conservadora, según el cual las demandas sociales solo serían la reacción posterior a una agresión político-delictiva. Esta omisión es útil para recuperar la confianza de aquellos ciudadanos que consideran legítimas las demandas, pero que no concuerdan con la idea de una nueva Constitución.

Un segundo tema de la "Declaración" es la resistencia al laicismo. Este argumento es de orden comunitario en la medida en que responde al interés propio del grupo que lo emite. En efecto, afirman los firmantes que:

Es de público conocimiento que aquellos sectores más ideológicos que desean una nueva constitución quieren pasar de un estado laico a un estado laicista, ignorando a Dios y suprimiendo todo aquello que se relacione con la religión o profesión de una fe ("Declaración de Concepción" cit. en Líderes de iglesias evangélicas en Chile..., 2020, enero).

Los firmantes sostienen que hay sectores interesados en que una nueva Constitución "ignore" a Dios en distintas materias de la vida civil y pública. Son citados diversos casos de proyectos de leyes que serían parte de un proceso sostenido por coartar la libertad religiosa, desde la idea de reformar la Ley de 
Culto 19.638 hasta un proyecto de "ley mordaza" que restringiría ciertas expresiones habituales de los actores evangélicos. La vinculación semántica entre "sectores más ideológicos", "nueva Constitución" e "ignorar" a Dios, no es en absoluto casual. Este párrafo es tal vez el más sugerente. No es infrecuente encontrar el término "ideología" utilizado en un sentido negativo para referirse a sectores de izquierdas, usualmente desde posiciones más conservadoras. Sin embargo, en este caso aquello es históricamente más complejo, porque desde un punto de vista comparado, el lenguaje utilizado en este párrafo es similar al utilizado por actores evangélicos que respaldaron el régimen militar. Por ejemplo, un relevante actor prodictadura desde los primeros días, refiriéndose a los evangélicos ecuménicos históricamente contestatarios al régimen militar, señaló en sus memorias que ellos: "desarrollaron su campo de acción en la defensa de los derechos humanos, que de cierto modo no era una preocupación central del resto de los líderes e iglesias, que no estábamos acostumbrados a lideranzas ideológicas y políticas" (Canales, 2000, p. 85). A la vez, el uso de "ideología" en sentido negativo estaba vinculado directamente a la cuestión del "ateísmo". Como quedó preclaramente plasmado en el documento "Posición Evangélica de 1974", firmado por una treintena de obispos y pastores en representación de diversas iglesias en apoyo al régimen, ese sector evangélico consideraba que el marxismo era un peligro para la fe porque se trataba de una ideología atea (Aránguiz, 2014).

Aunque no es esta la ocasión para ver el grado de vinculación que pudiese haber entre los actores contemporáneos con los del pasado, sí es posible señalar que el uso negativo de "ideología" en el discurso evangélico de derechas contemporáneo del modo en que se usa en la "Declaración de Concepción", junto con su interpretación del proceso constituyente, como uno que pone en riesgo el ejercicio de la fe son sugerentes. Guardando las proporciones, podría decirse que, del mismo modo que en décadas anteriores el apoyo al régimen militar fue indisociable de la oposición a la ideología marxista internacional por promover el ateísmo, la defensa de la Constitución 
vigente es, a su vez, indisociable de la oposición a las ideologías que ignoran a Dios -llámese laicistas-, que estarían tras la nueva Constitución.

Por último, la Declaración señala que:

El mundo cristiano, por esencia es reformador y no revolucionario. Considera que las antiguas generaciones, sean estas de uno u otro sector político, nos han dejado experiencia, reflexiones y conocimiento útil. Es ilógico abandonar todo lo que hemos hecho bien como país; también porque al partir de una "hoja en blanco" da mucho lugar a perder derechos y libertades que están expresadas en nuestra actual Constitución, en lo económico y también en lo valórico. Pensamos que lo mejor es continuar reformando la Constitución. ("Declaración de Concepción" cit. en Líderes de iglesias evangélicas en Chile..., 2020, enero).

Este argumento es conservador en la medida que entiende el desarrollo social en una clave orgánica y de aprendizaje generacional. A su vez, añade un elemento identitario propio del mundo evangélico que es el de la "Reforma", aludiendo de algún modo al espíritu de los reformadores protestantes. Aparece claramente el argumento de la "hoja en blanco", expresión que designa la idea según la cual una nueva Constitución pondría en riesgo todo aquello que ha dado estabilidad al país en cuanto que su contenido sería enteramente definido por los constituyentes, sin atender a elementos que fueron formulados $y$ defendidos por la Constitución vigente.

En otro sentido, cabe señalar dos documentos emitidos por iglesias evangélicas, una "Declaración pública de la Iglesia Metodista de Chile" (IMECH) y una "Carta pastoral” emitida por la Iglesia Evangélica Presbiteriana de Chile (IEPECH). Ambas fueron emitidas poco después de la "Declaración de Concepción" y en ambas se encuentran contenidos similares que responden a dicha Declaración. En tal sentido, ambas iglesias se posicionan a favor de la formulación de una nueva Constitución. Esta divergencia no se explica simplemente como un modo de marcar distancia con el sector vinculado a la derecha en la contingencia. Más bien, es preciso señalar que ambas iglesias arrastran consigo una historia de posicionamiento político que viene desde los 
tiempos de la dictadura militar, tiempo en el cual tuvieron una activa promoción de los derechos humanos. En efecto, aunque no es este el lugar para examinar en detalle las continuidades, cabe al menos dejar nota de que ambas iglesias estuvieron representadas en la firma de la "Carta Abierta" al General Augusto Pinochet el 29 de agosto de 1986, gestionada por la Confraternidad Cristiana de Iglesias (CCI), organización ecuménica con una posición contestataria al régimen militar (Mansilla, Sepúlveda y Orellana, 2015). En ella se denunciaba una serie de asuntos entre los cuales se encuentra la desigualdad socioeconómica y la violencia estatal, entre otros temas. Al igual que con la "Declaración de Concepción", es posible notar que, en las cartas recogidas a favor de un proceso constituyente contemporáneo, también hay reminiscencias con el discurso de los días de dictadura. Aunque no es este el lugar para hacer comparaciones exhaustivas, sí cabe mostrar algunas coincidencias a modo de ejemplo.

Por otra parte, resulta relevante el hecho de que la IMECH y la IEPECH utilicen el género de la carta pública, pues da cuenta de una continuidad con la CCI. Esto porque dicha organización utilizó frecuentemente esa estrategia de posicionamiento público, publicando diez cartas entre 1983 y 1988 (Mansilla, Sepúlveda y Orellana, 2015). Así, puede decirse que la IMECH y la IEPECH mantienen una continuidad con la tradición ecuménica de la que formaron parte en el pasado, tanto en su toma de posición política como en su estrategia de posicionamiento público. De este modo, no resulta extraño que ambas iglesias nuevamente adopten posiciones que parecen cercanas o identificables con las izquierdas, sector político que se caracteriza por apoyar y promover transversalmente una nueva Constitución.

La "Declaración de la IMECH" se realizó en el marco de la Asamblea General de dicha Iglesia, que tuvo lugar entre los días 15 y 19 de enero de 2020. Cabe señalar que también tuvo resonancia mediática debido a que se la mostró como una respuesta a la "Declaración de Concepción". El texto de la IMECH se compone de 10 puntos que se articulan en torno a lo que denominamos una narrativa de la rectificación. En su punto dos, el texto señala: 
"Como cristianos metodistas no podemos desmarcarnos de la responsabilidad social que tenemos, sobre todo aquella que ha suscitado la crisis que como país estamos viviendo, por lo que asumimos como nuestra la responsabilidad en torno de este contexto" (IMECH, 2020, p. 1). Desde un principio, el metodismo ha tenido entre sus fuertes el compromiso social, por lo cual es natural que la IMECH reconozca esa responsabilidad, y es precisamente el reconocimiento de ese compromiso el que al parecer en el punto 4 lleva a los firmantes a manifestar arrepentimiento:

Con humildad pedimos perdón por no haber sido una Iglesia que haya develado el pecado de la injusticia social, en todas sus esferas, con mayor prontitud y vehemencia. Constatamos que el estallido social hizo emerger y visibilizar una crisis profunda, la que es reflejo de una sociedad hedonista, individualista y materialista. (IMECH, 2020, p. 1).

Luego, se plantea una serie de críticas: al sistema económico chileno, al hecho de que la sociedad chilena es patriarcal, se llama la atención respecto a la crisis medioambiental y se cuestiona el modo en que la élite política chilena ha tratado a los pueblos originarios. Tras todo ello, el texto pasa a denunciar la violencia que ha venido con el estallido:

Nos ha horrorizado la violencia destructiva por parte de los agentes del Estado, que está dejando secuelas de mujeres y hombres violentados y mutilados, además de otras consecuencias fatales (...) Nos preocupa que el estallido social ha traído consigo una violencia inusitada de algunos sectores interesados en perturbar la sana convivencia social. (IMECH, 2020, p. 2).

Resulta interesante notar en este caso el orden de la condena a la violencia. Si bien se cuestiona a "algunos sectores interesados en perturbar la sana convivencia social", no se los menciona directamente. Por otra parte, estos sectores son mencionados solo después de dejar nota de la violencia de agentes del Estado. La mención explícita a un actor en su mención, y no a otro, muestra una diferencia de énfasis respecto al objeto de cuestionamiento del documento. En lo que toca a la denuncia de la violencia de Estado, en particular, la 
declaración de la IMECH sigue el discurso de la "Carta Abierta" de la CCI de 1986, la cual afirmaba: "hemos constatado en repetidas oportunidades que vuestro gobierno en vez de procurar escuchar y reconocer las razones del descontento popular, ha concentrado todo su esfuerzo en la incomprensible tarea de inhibir, reprimir, desvirtuar y desconocer toda forma de manifestación popular" (Varios Autores [VV.AA.], 29 de agosto de 1986, p. 175).

La diferencia de énfasis entre la violencia de Estado y la violencia de "algunos sectores" se podría en parte comprender bastante mejor atendiendo a la solicitud de perdón que la IMECH hace por su falta de denuncia de las injusticias. En efecto, resulta lógico que en esta oportunidad la IMECH quiera rectificarse denunciando "con prontitud y vehemencia", como dice antes en el punto 4, las injusticias.

Finalmente, es en ese mismo tenor que la "Declaración" de la IMECH afirma en su punto 10 el compromiso con una nueva Constitución: "nos comprometemos a promover y participar activamente en el proceso de construcción de una nueva carta fundamental, que incluya la mirada de todos y todas" (IMECH, 2020, p. 3). Esta adherencia irrestricta al proceso por una nueva Constitución inclusiva puede leerse a la luz de la narrativa de la rectificación que la IMECH elabora en su carta. En este llamado incluyente puede también verse una continuidad con el la "Carta abierta" de 1986, en la que se señalaba: “estamos convencidos de que la única forma de detenerla [la violencia] es abriendo las puertas a la plena participación ciudadana en la búsqueda de un consenso para la reconstrucción de un país de hermanos que ha dejado de ser tal" (VVAA, 1986, p. 176).

Las diferencias entre la "Declaración" de la IMECH y la "Carta pastoral" de la IEPECH son menores, pero sirven para ilustrar cómo la narrativa de la rectificación de la IMECH es distintiva. En efecto, el documento de la IEPECH también es fruto de un evento institucional, el Sínodo que realizaron entre los días 17 y 19 de enero de 2019, casi en paralelo con la Asamblea General de la IMECH. En esta "Carta", si bien se aboga por una nueva Constitución al igual que en la "Declaración" de la IMECH, no se encuentra sin 
embargo una solicitud de perdón. Por lo tanto, la construcción del argumento es distinta. La IEPECH exhibe una narrativa de la participación:

nos sumamos, como parte del cuerpo de Cristo, en la búsqueda de una nueva sociedad, en la tarea y desafío que significa contribuir a realizar cambios profundos en nuestro país. Del mismo modo queremos participar, apoyar, elaborar y aprobar una nueva Constitución política para nuestro país en la cual se plasmen los altos valores y principios de sociedades modernas, democráticas y que garantice los deberes y derechos de quienes vivimos y amamos este país. (IEPECH, 2020, p. 2).

Un segundo elemento en el que claramente se nota la diferencia con la IMECH y su narrativa, es que su condena a la violencia está articulada de otro modo. El texto señala:

Lamentamos y condenamos los hechos de violencia que hemos visto, así como las acciones que realizan los órganos del Estado ante las manifestaciones sociales. Del mismo modo, pedimos a cada persona que se manifiesta que lo haga pensando en el bien mayor y tomando en consideración que se busca cambiar un modelo agotado, por uno que responda a lo nuevo, a lo que soñamos. La destrucción y la violencia no son los caminos que nos conduzcan a un nuevo país. (IEPECH, 2020, p. 2).

Como puede observarse, la "Carta pastoral" coloca en general "hechos de violencia" para enfocarse después en "las acciones que realizan los órganos del Estado". Asimismo, la "Carta" no se limita a denunciar difusamente a "algunos sectores interesados en perturbar la sana convivencia social” sin más como hace la "Declaración" de la IMECH, sino que hace un requerimiento "a cada persona que se manifiesta" a que lo haga con una cierta conciencia de su lugar en la vida comunitaria. De este modo, la "Carta" de la IEPECH señala con claridad que los manifestantes tienen una responsabilidad en evitar la violencia.

Vistas estas tres declaraciones, es interesante considerar una interpretación de la reacción de estas entidades evangélicas en relación con la crisis de credibilidad de las instituciones religiosas en Chile y el estallido social. 
Por una parte, si bien la "Declaración de Concepción" proviene de un sector evangélico vinculado a las derechas, no se alinea enteramente con la hipótesis "antiestallido" de Muñoz (2019). Esta estrategia le permite intentar una recuperación de confianza mediante la solidarización con las demandas sociales, pero al mismo tiempo su carácter reformista respecto a la Constitución vigente le permite mantenerse en los límites de las derechas, distanciándose así del carácter "revolucionario" de una nueva Constitución.

Por su parte, los documentos de la IMECH y la IEPECH muestran también un esfuerzo por recuperar la confianza de la ciudadanía. En estos casos, no se recurre solamente a una solidaridad con las demandas, sino que se llega a la conclusión de que el modo efectivo de llevarlas a cabo es una nueva Constitución, adhiriendo así a la narrativa dominante del estallido social (Garcés, 2020). Esta estrategia, en el caso de la IEPECH, se construye como una narrativa de la participación de dicha iglesia y su perspectiva cristiana, en el proceso de una nueva Constitución. En el caso de la IMECH, no obstante, la estrategia de recuperación de confianza se lleva a cabo mediante una narrativa de la rectificación según la cual los cristianos tienen una culpa que exige una solicitud de perdón, que es lo que la IMECH realiza en su "Declaración".

Aunque ya una mirada superficial revela las diferencias temáticas y de énfasis de cada una de ellas, hay varios elementos que comparten. El esfuerzo de posicionamiento público del que se ha dado cuenta aquí puede entenderse como una réplica a menor escala del debate nacional. Si bien es cierto que los discursos religiosos, como es esperable y como ocurre aquí también, suelen estar cargados de referencias bíblicas y teológicas, en los casos seleccionados no se han observado variaciones sustantivas respecto a los enfoques dominantes del debate Apruebo/Rechazo. En tal sentido, el esfuerzo de posicionamiento público en estos casos ha implicado adherir a una u otra de las tendencias ya instaladas desde una argumentación cargada de lenguaje religioso, más que esbozar una comprensión propiamente teológica de la situación en su conjunto. Ciertamente, las religiones no han desaparecido del ámbito público como las teorías de secularización habrían esperado (Berger, 1990). Ellas siguen 
otorgando sentido. Desde siempre las instituciones religiosas se han visto inclinadas a tomar posiciones, pero a diferencia del pasado, tal vez el riesgo de marginalidad al que se ven sometidas en el mundo moderno, sea también un aliciente para su búsqueda de relevancia. De aquí que tal vez el tomar posiciones claras en contextos de crisis pueda ser una estrategia para evitar una importancia marginal.

Por último, es posible constatar que los textos contemporáneos seleccionados exhiben reminiscencias y continuidades con estrategias y con discursos evangélicos del pasado reciente de uno y otro sector. Esto puede notarse en el modo de posicionamiento (la carta o declaración), en materia de contenido y énfasis, así como en terminología clave. Estas continuidades no implican en modo alguno que no existan también discontinuidades, pero sí ayudan a leer en perspectiva histórica la participación de las organizaciones del presente y, en especial, sus técnicas de uso del lenguaje en el ámbito público.

\section{Conclusiones}

La desaparición de la religión ha sido una de las versiones de las teorías de la secularización más refutadas en la actualidad. Basada en el razonamiento posilustrado que supeditaba la emancipación del individuo y la sociedad a la hegemonía de la razón técnica, la religión aparecía como la base de toda forma de conocimiento y organización tradicional cuyo fin último sería su superación. En otros términos, el avance de la razón en todos los ámbitos de la vida personal y colectiva (incluida la política a través del desarrollo de la burocracia moderna, por ejemplo) pronosticaba un agotamiento funcional de la religión que la haría innecesaria en un momento determinado. Aunque es posible encontrar casos de países en los que la filiación religiosa ha decaído en términos absolutos frente a la increencia el último siglo (Chile incluido), no se necesitan demasiados ejemplos para demostrar no solo que la religión sigue existiendo en sus formas individuales, colectivas e institucionales, sino también que razón y religión no implican relaciones necesariamente excluyentes. 
Si bien las teorías de la secularización cuestionaron la relevancia y vigencia de lo religioso en el espacio público en la sociedad contemporánea, el papel que las instituciones eclesiales y sus liderazgos han jugado en la construcción histórica de la nación resultan incuestionables. Sin embargo, lo que está en debate en la actualidad es el nivel de incidencia y penetración de su discurso y su capacidad de diálogo respecto de las demandas de una ciudadanía cada vez más compleja y diversa.

La incapacidad para reaccionar de manera oportuna de las instituciones eclesiales ante el estallido social, iniciado en octubre de 2019 en Santiago de Chile, no solo demuestra la falta de sintonía para responder a las problemáticas estructurales que han configurado el modelo societal posdictadura (desigualdad, pobreza, inequidad, entre otros), sino también, permite retratar con mayor claridad la pluralidad de formas que los sujetos utilizan para vincularse con lo religioso: desde su identificación nominal con la religión hasta la búsqueda personal del sentido de comunidad extraviado a través de colectivos políticos, ONG, agrupaciones ecologistas, feministas, animalistas, etc.

El bajo nivel de exposición pública de las iglesias (católica y evangélicas) durante las primeras semanas de la convulsión social, motivado por el cuestionamiento público hacia todas las instituciones por parte de la ciudadanía, les significó no solo restarse del debate para la resolución del conflicto, debido a la frágil confianza depositada en ellas, sino también demostró una vez más su pérdida de relevancia como agente mediador de conflictos en el Chile actual, ya que es su sitial en la sociedad lo que está en cuestionamiento.

Los abusos de poder, conciencia y sexuales no solo han evidenciado acciones delictuales y graves faltas éticas, también han permitido indagar en los privilegios, desigualdades y acciones discriminatorias al interior de sus propias instituciones. La presencia de una doble moral pontificadora externa para la sociedad no parece encontrar réplica intragrupalmente en sus propias iglesias. Este hecho, a nuestro juicio, ha dañado de manera casi irreparable la confianza que las instituciones eclesiales habían forjado en su relación con la sociedad a 
través de décadas en Chile, pues hoy son foco de cuestionamientos, críticas y rechazo. Ya no basta con la fe, se les exige consecuencia, transparencia y ajustes para empatizar con las problemáticas sociales que la sociedad padece en la cotidianeidad.

En algunos casos, al considerar los hechos retratados en el presente texto -el 18 de octubre y sus consecuencias-, se vislumbra el fortalecimiento de acciones religioso/espirituales en agrupaciones seculares más que religiosas. Pues, el sentido de hermandad, amor por el prójimo, comunidad, empatía, amor, etc. han encontrado respuestas de manera más efectiva a través de dichas instituciones que actúan de manera horizontal, sin liderazgos definidos y con bajas o nulas barreras de entrada.

Un caso paradigmático es el que se presenta con la serie de declaraciones realizadas por agrupaciones evangélicas meses después del estallido social. Ante la posibilidad de plebiscitar una nueva Constitución emanada de la ciudadanía, algunas de ellas visibilizaron sus posturas políticas irrumpiendo en el espacio público físico y virtual. Consignas de rechazo y aprobación se cruzaron con lecturas políticas y teológicas en las que quedó plasmado, para un sector, el temor de una amenaza a su Constitución como iglesias y a la libertad de culto, así como, para otro sector, el deseo por rectificar lo que consideran una falta de esfuerzo en denunciar las injusticias sociales. Cualquiera sea la posición, es posible constatar que, entre las organizaciones evangélicas interesadas en participar de la vida pública del país, hay aquellas que han enfrentado el nuevo contexto catapultado por octubre de 2019, recurriendo a estrategias tradicionales de posicionamiento como las cartas y declaraciones públicas. El recurso a este tipo de estrategia muestra que la intencionalidad por participar de la vida pública sigue comprendiéndose, con más o menos matices, de acuerdo con esquemas que son desafiados por la cultura de redes sociales y que exigen una adaptación. De aquí que, si bien el género de carta se mantiene, el documento puede circular por sitios webs institucionales e incluso páginas institucionales en redes sociales como Facebook. 
En términos de proyecciones futuras, es dable señalar que si bien en general suele prestarse atención al estudio del mundo evangélico en perspectiva histórica y contextual, como es este caso, la complejidad discursiva y las herramientas de análisis con las que se cuenta en el presente, hacen necesario un estudio del mundo evangélico también en términos de su historia discursiva. Esto permitiría detectar desde otro punto de vista las diversas continuidades y discontinuidades que se han dado en el tránsito del posicionamiento público evangélico en Chile.

El 18 de octubre encontró a las instituciones religiosas en un momento crítico único desde el regreso a la democracia. Por lo tanto, el comportamiento público de las iglesias y actores religiosos a dicho evento tiene que comprenderse no solo como reacción a una contingencia más, sino como un modo de construir o recuperar confianza frente a la ciudadanía y sus propias feligresías. En este sentido específico, es posible decir que hay instituciones religiosas y actores que no solo han hecho ver su interpretación de los hechos, sino que han aprovechado el estallido social como una oportunidad para ocupar nuevos espacios disponibles dentro de un campo político fracturado y un espacio público en reestructuración. En este sentido, más allá de si las lecturas y propuestas evangélicas presentan mayor o menor grado de originalidad y eficacia respecto de otros discursos circulantes en el actual contexto de crisis, creemos posible afirmar la emergencia de un nuevo momento de posicionamiento público evangélico al amparo de la crisis de confianza de las instituciones religiosas, en particular, y la política formal, en general. Al tiempo que la Iglesia católica aparece silente y entrampada en sus propias crisis internas, evidenciando el colapso de su liderazgo y capital político-social acumulado por siglos, algunos agentes evangélicos ven la oportunidad de erigirse como referentes sociales y morales en medio de la confusión y el conflicto. Aunque no es posible generalizar esta actitud a la universalidad del mundo evangélico o protestante, el cual también ha experimentado procesos de crisis profunda en algunas iglesias históricas a nivel nacional, sí se puede observar una recomposición de las relaciones entre religión y política al amparo 
de las contradicciones y limitaciones de la democracia chilena evidenciadas desde el pasado 18 de octubre de 2019.

\section{Referencias bibliográficas}

Ammerman, N. (1994). Telling Congregational Stories. Review of Religious Research, 35(4), 289-301.

Aránguiz, L. (2014). El evangelio pinochetista: una indagación en torno al discurso institucional evangélico chileno pro-dictadura militar. En P. Fogelman y M. F. Contardo (eds.), Actas electrónicas del V SIRCP: Quinto Simposio Internacional sobre Religiosidad, Cultura y Poder (pp. 60-83). Buenos Aires: Ediciones del GERE.

Bahamondes, L. (2017). Institucionalidad religiosa en tiempos de crisis: desconfianza, filiaciones difusas y búsquedas de sentido en el Chile actual. En A. Vera (ed.), Malestar y desigualdades en Chile (pp. 227249). Santiago: Ediciones Universidad Alberto Hurtado.

Bahamondes, L. (9 de marzo de 2020). Ser evangélico no es ser de derecha: las complejidades de un credo usualmente desestimado por la izquierda. CIPER. [En línea]. Recuperado de https://ciperchile.cl/2020/03/09/serevangelico-no-es-ser-de-derecha-las-complejidades-de-un-credousualmente-desestimado-por-la-izquierda/\#_ftn7

Berger, P. (1990). The Sacred Canopy. Elements of a Sociological Theory of Religion. Nueva York: Anchor Books.

Berger, P. y Luckmann, P. (1997). Modernidad, pluralismo y crisis de sentido. Barcelona: Paidós.

Bruce, S. (2010). Secularization. Oxford: Oxford University Press.

Calhoun, C. (2011). Afterword: Religion's many powers. En E. Mendieta y J. Van Antwerpen (eds.), The Power of Religion in the Public Sphere (pp. 118-134). Nueva York: Columbia University Press.

Campos, M. (2007). Globalización y secularización. Revista Cultura \& Religión, 1(1), 108-125. 
Canales, H. (2000). Firmes y adelante. Santiago: Barlovento.

Casanova, J. (1994). Public Religions in the Modern World. Chicago y Londres: The University of Chicago Press.

Casanova, J. (2012). Genealogías de la secularización. Barcelona: Anthropos Editorial.

CEP (2019) Estudio Nacional de Opinión Pública $n^{\circ}$ 84. Encuesta CEP. Santiago: CEP. Recuperado de https://www.cepchile.cl/cep/site/docs/20200116/20200116081636/encue stacep_diciembre2019.pdf

Cortés, L. y Camacho, M. (2003). ¿Qué es el análisis de discurso? Barcelona: Octaedro-EUB.

Eggins, S. (2002). Introducción a la lingüística sistémica. Logroño: Universidad de La Rioja.

Fairclough, N. (1992). Discourse and Social Change. Cambridge: Polity Press.

Fediakova, E. y Parker, C. (2009). Evangélicos en Chile democrático (19902008): Radiografía al centésimo aniversario. Revista Cultura \& Religión, 3(2), 43-69.

Felipe Berríos sobre el estallido social: "Hay una Iglesia que no entiende lo que hoy está pasando". (15 de febrero de 2020). El Desconcierto. [En línea]. Consultado el 10 de marzo de 2020. Recuperado de https://www.eldesconcierto.cl/2020/02/15/felipe-berrios-sobre-elestallido-social-hay-una-iglesia-que-no-entiende-lo-que-hoy-estapasando/

Garcés, M. (2020). Estallido social y una nueva Constitución para Chile. Santiago: LOM.

Habermas, J. (2011). The political: The rational meaning of a questionable inheritance of political theology". En E. Mendieta y J. Van Antwerpen (eds.), The Power of Religion in the Public Sphere (pp. 15-33). Nueva York: Columbia University Press.

Herrera, H. (2019). Octubre en Chile. Santiago: Katankura. 
Iglesia Evangélica Presbiteriana de Chile (IEPCH) (2020). Carta Pastoral. [En línea]. Consultado el 22 de marzo de 2020. Recuperado de http://ctedechile.cl/wp-content/uploads/2020/01/Carta-Pastoral-IEPCh2020-2.pdf

Iglesia Metodista de Chile (2020). Declaración Pública de la Iglesia Metodista de Chile. Sitio web de la Iglesia Metodista de Chile. [En línea]. Consultado el 22 de marzo de 2020. Recuperado de https://www.metodistachile.cl/2020/01/23/declaracion-publica-de-laiglesia-metodista-de-chile/

Programa de las Naciones Unidas para el Desarrollo (PNUD) (2002). Desarrollo humano en Chile. Nosotros los chilenos: un desafío cultural. Santiago: PNUD.

Inglehart, R. (2009). Cultural change, religion, subjective well-being, and democracy in Latin America. En F. Hagopian (ed.), Religious Pluralism, Democracy, and the Catholic Church in Latin America (pp. 69-75). Indiana: University of Notre Dame Press.

Juergensmeyer, M. (2001). Terror in the Mind of God. The Global Rise of Religious Violence. Berkeley, Los Angeles, Londres: University of California Press.

Levine, D. y Stoll, D. (1995). Religious change, empowerment, and power: Bridging the gap in Latin America. Journal of Iberian and Latin American Research, 1(1-2), 1-33.

Levine, D. (2012). Politics, Religion and Society in Latin America. Boulder y Londres: Lynne Rienner Publishers.

Lincoln, B. (2003). Holly Terrors. Thinking About Religion After September 11. Chicago y Londres: The University of Chicago Press.

Luckmann, T. (1967). The Invisible Religion: The Problem of Religion in Modern Society. Nueva York: The Macmillan Company.

Mallimaci, F. (2013). Prólogo. El desafío de consolidar desde América latina nuevos paradigmas en el estudio de nuestras sociedades y religiones. En V. Giménez Béliveau y E. Giumbelli (coords.), Religión, cultura y 
política en las sociedades del siglo XXI (pp. 17-23). Buenos Aires: Biblos.

Mansilla, M., Sepúlveda, J. y Orellana, L. (2015). Cuando el opio se rebela: La Confraternidad Cristiana de Iglesias (evangélicas) en su crítica a la dictadura militar y su proyecto de sociedad (1981-1989). Revista de Ciencia Política, 35(2), 327-345.

Martin, D. (2005). On Secularization. Towards a Revised General Theory. Farnham, UK: Ashgate Publishing Limited.

Matamala, D. (2019). La ciudad de la furia. Santiago: Catalonia-Periodismo UDP.

Mayol, A. (2019). Big bang. Estallido social 2019. Modelo derrumbado. Sociedad rota. Política inútil. Santiago: Catalonia.

Morello, G., Romero, C., Rabbia, H. y Da Costa, N. (2017). An Enchanted Modernity: Making sense of Latin America's Religious Landscape. Critical Research On Religion, 5(3), 308-323.

Moulian, T. (1998). El consumo me consume. Santiago: LOM.

Moulian, T. (2002). Chile actual: anatomía de un mito. Santiago: LOM.

Muñoz, S. (2020). La democracia necesita defensores. Santiago: Ediciones El Líbero.

Neuhaus, R. (1984). The Naked Public Square: Religion and Democracy in America. Michigan: William B. Eerdmans Publishing Company.

Peterson, A. (1996). Religious narratives and political protest. Journal of the American Academy of Religion, 64(1), 27-44.

Peterson, A., Vásquez, M. y Williams, P. (2001). Christianity and social change in the shadow of globalization”. En A. Peterson, M. Vásquez y $\mathrm{Ph}$. Williams (eds.), Christianity, Social Change, and Globalization in the Americas (pp. 1-22). New Brunswick, New Jersey y Londres: Rutgers University Press.

Pew Research Center. (2014). Religion in Latin America: Widespread Change in a Historically Catholic Region. Sitio web del Pew Research Center, Sección Religion. [En línea]. Consultado el 16 de abril de 2020. 
Recuperado de https://www.pewforum.org/2014/11/13/religion-in-latinamerica/

Pontificia Universidad Católica (PUC). (2019). Encuesta Nacional Bicentenario Universidad Católica. [en línea]. Consultado el 19 de marzo de 2020. Recuperado de https://encuestabicentenario.uc.cl /resultados/

Pratt, D. (2018). Rejection and Extremism: Rejecting Diversity. Nueva York y Londres: Bloomsbury.

Rawls, J. (1997). The idea of public reason revisited. The University of Chicago Law Review, 64(3), 765-807.

Rivera, C. (2014). La religión también es política. Un acercamiento a la acción política de indígenas evangélicos de Chiapas, México. Revista Cultura \& Religión, 8(1), 47-64.

Rubin, J., Smilde, D. y Junge, B. (2014). Lived religion and lived citizenship in Latin America's zones of crisis. Latin American Research Review, 49, Special Issue, 7-26.

Sandoval, G. (2018). Chile: Avance evangélico desde la marginalidad al protagonismo. En J. L. Pérez Guadalupe y S. Grundberger (eds.), Evangélicos y poder en América (pp. 181-220). Lima: Latina. Konrad Adenauer Stiftung (KAS)-Instituto de Estudios Social Cristianos (IESC).

Semán, P. (2013). Pentecostalismo, política, elecciones y poder social. Revista Cultura \& Religión, 7(1), 60-81.

Sepúlveda, J. (1999). De peregrinos a ciudadanos. Santiago: Konrad Adenauer. Taylor, C. (2011). Why we need a radical redefinition of secularism. En E. Mendieta y J. Van Antwerpen (eds.), The Power of Religion in the Public Sphere (pp. 34-59). Nueva York: Columbia University Press.

VV. AA. (29 de agosto de 1986). Carta Abierta. [Capitán General Don Augusto Pinochet Ugarte]. En M. Mansilla y L. Orellana (2019), Evangélicos y política en Chile 1960-1990 (pp. 173-178). Santiago: RIL-UNAP. 
Watanabe, J. (2009). El Reino de Dios como utopía. Las protestas y propuesta de Jesús frente al reino político. Revista Cultura \& Religión, 3(1), 112124.

* El presente artículo se enmarca en el desarrollo del proyecto FONDECYT Regular $\mathrm{n}^{\circ}$ 1180359 "Nuevas mercancías y servicios religiosos en Santiago: Prácticas, consumo y resignificaciones de lo sagrado" de ANID, Chile.

* Doctor en Ciencias de las Religiones, Universidad Complutense de Madrid, España. Académico del Centro de Estudios Judaicos de la Universidad de Chile y del Centro de Investigaciones Socioculturales (CISOC) de la Universidad Alberto Hurtado. Sus áreas de especialización son el estudio del fenómeno religioso latinoamericano y sus vínculos con los procesos políticos, económicos, sociales y culturales en la región. lubahamo@u.uchile.cl

"* Licenciado en Letras Hispánicas, Pontificia Universidad Católica de Chile. Magíster en Estudios Internacionales del Instituto de Estudios Avanzados, Universidad de Santiago de Chile. Sus áreas de interés investigativo son la relación entre literatura y religión, el discurso político religioso evangélico, así como la actividad política religiosa en perspectiva internacional. luis.arka@gmail.com

${ }^{* * * * *}$ Licenciado en Historia y magíster en Ciencias Sociales mención en Sociología de la Modernización, Universidad de Chile. Doctorando en Religión en las Américas, The University of Florida. Profesor adjunto del Centro de Estudios Judaicos de la Universidad de Chile. Sus intereses de investigación y docencia incluyen catolicismo y pentecostalismo latinoamericano, religión en contexto de presidio, nuevos movimientos religiosos, religión y política, teoría de la religión, religión y educación, entre otros.nmarin@uchile.cl 